\title{
Wearable antenna gain enhancement using reactive impedance substrate
}

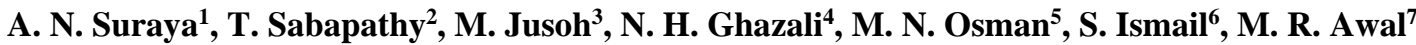 \\ $1,2,3,4,5,6$ Bioelectromagnetic Research Group (BioEM), School of Computer and Communication Engineering, \\ Universiti Malaysia Perlis, Malaysia \\ ${ }^{7}$ School of Ocean Engineering, Universiti Malaysia Terengganu (UMT), Malaysia
}

\begin{tabular}{l} 
Article Info \\
\hline Article history: \\
Received Oct 12, 2018 \\
Revised Nov 10, 2018 \\
Accepted Nov 26, 2018 \\
\hline
\end{tabular}

\section{Keywords:}

Microstrip patch antenna Reactive impedance substrate

Textiles antenna

Wearable antenna

\begin{abstract}
A microstrip patch antenna is designed for a wearable antenna. The performance of microstrip patch antenna loaded with reactive impedance surface (RIS) is described in terms of gain, bandwidth and return loss. The antenna is investigated in two conditions which are conventional microstrip antenna with RIS and without RIS. The designed antenna is also aimed at size reduction therefore it will be suitable for a wearable application. This antenna which is made fully using textile and it is designed for operation in the 2.45 $\mathrm{GHz}$ band. The performance of microstrip patch antenna loaded with RIS is described in terms of gain, bandwidth, return loss and radiation pattern. The antenna designed with RIS operates at $2.45 \mathrm{GHz}$. Bandwidth enhancement is achieved with RIS where the designed antenna can cater frequency from 2.4 $\mathrm{GHz}$ to $3 \mathrm{GHz}$. A gain enhancement is achieved of $20 \%$ is achieved compared with the conventional patch antenna. Although the size of the patch is reduced with the introduction of RIS, the overall size of the antenna with the substrate is almost similar to the conventional patch antenna. However, the performance of the antenna is greatly enhanced with the use of RIS.
\end{abstract}

Copyright (c) 2019 Institute of Advanced Engineering and Science. All rights reserved.

\section{Corresponding Author:}

M. Jusoh,

Bioelectromagnetics Research Group (BioEM),

School of Computer and Communication Engineering,

Universiti Malaysia Perlis (UniMAP),

Kampus Pauh Putra, 02600, Arau, Perlis, Malaysia.

Email: muzammil@unimap.edu.my

\section{INTRODUCTION}

A wearable antenna is an antenna that is specifically designed to function while being worn on body wearable fabric/textile antenna is one of the dominant research topics for body centric communication. In particular, with the recent advancement of Internet of Thing (IoT) technology, the developments of wearable electronic devices such as antennas are gaining popularity among the researchers. A simple microstrip patch antenna consists of a radiating patch on one side of a dielectric substrate and a ground plane on its other side. Such antenna is suitable for body-worn applications because it mainly radiates perpendicularly to the planar structure and the ground plane efficiently shields the body tissues.

However, the antenna design for wearable application is quite crucial. First, the size of the designed antenna is quite bulky since it is designed with wearable material which has low relative permittivity [1]. Apart from that, it is also important to achieve good antenna performance when it is designed with the wearable material [2]. The problem could be also further challenging if multi element antenna has to be designed for a wearable application that could support emerging communication technologies such as beam steering [3], IoT [4] and MIMO [5]. This can lead to antenna design which has a larger size. On the other hand, the evolution in metamaterial gives advantages to antenna design in many aspects such as high gain, high bandwidth and miniaturization [6-7]. 
In work [8] metamaterial is used to introduced metamaterial in wearable antenna design for WLAN application. In this paper, the introduction of the metamaterial is expected to miniature the wearable antenna. Based on through literature review, it is known that reactive impedance substrate (RIS) can miniaturize the size of the antenna [9]. Therefore, it is chosen as the method to design the wearable antenna. RIS is also known as 2D metamaterial where it can be considered as a thin layer. Rectangular shaped RIS array is easily developed where the desired antenna performances can be easily achieved. The designed RIS have the ability to reflect total power like PEC or PMC surfaces and at the same time be able to store magnetic or electric energy. Miniaturization is achieved by combining the reactive characteristic of the RIS with the capacitive (inductive) behavior in order to tune the resonance to a lower frequency.

The rest of the paper is organized as follows. The method involved in the antenna design is presented in Section 2. Section 3 presents the results and discussion. Finally, some conclusion remarks are given in Section 4.

\section{RESEARCH METHOD}

\subsection{Conventional Microstrip Patch Antenna}

The The structure of a conventional microstrip patch antenna is shown in the Figure.1. Felt fabric is used as the substrate where its thickness is $3 \mathrm{~mm}$, the dielectric constant is 1.4 and loss tangent is 0.002 . The patch and microstrip feedline dimensions are designed using well-known procedure as specified in [5] to ensure proper matching to a $50 \Omega$ SMA connector. Meanwhile, Shieldit is act as conductive material (patch, feedline and ground plane) are built. The properties of Shielit it is a high-quality flame-retardant fabric for radio frequency (RF) and the thickness is $0.17 \mathrm{~mm}$. It is features heat- activated glue on its reverse side which enables it to be ironed onto other substrate such as cotton or paper. The antenna is designed to operate at $2.45 \mathrm{GHz}$ frequency. 3D EM simuluation software is used to simulate the antenna. The optimized dimension of the antenna is tabulated in Table 1.

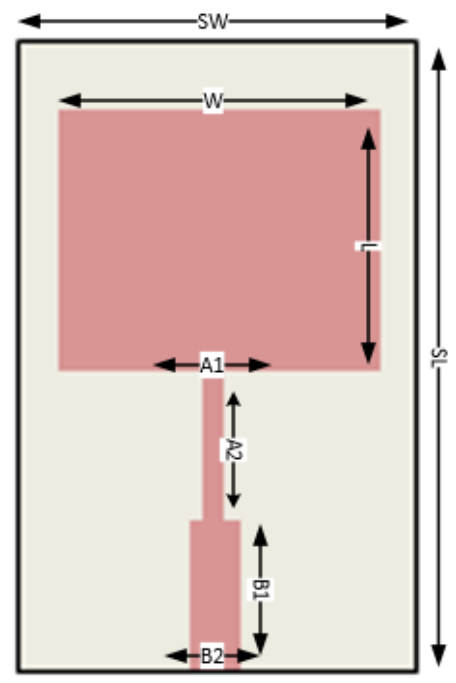

Table 1. Dimension of the Antenna

\begin{tabular}{ll}
\hline Parameters & \multicolumn{1}{c}{ Felt Fabric } \\
\hline Rectangular patch (L) & $45 \mathrm{~mm}$ \\
Rectangular patch (W) & $55 \mathrm{~mm}$ \\
Substrate (SL) & $110 \mathrm{~mm}$ \\
Substrate (SW) & $70 \mathrm{~mm}$ \\
Substrate thickness & $3 \mathrm{~mm}$ \\
Feed (B1) & $26.6 \mathrm{~mm}$ \\
Feed (B2) & $6.3 \mathrm{~mm}$ \\
Quarterwave (A1) & $2.9 \mathrm{~mm}$ \\
Quarterwave (A2) & $27 \mathrm{~mm}$ \\
\hline
\end{tabular}

Figure 1. Proposed conventional microstrip patch antenna

\subsection{Microstrip Patch Antenna with RIS}

To reduce the size of the antenna, a reactive impedance substrate is used [6]. In this paper, the RIS layer consists of $5 \times 5$ cross-shaped metallic unit cell patch array printed periodically on a grounded low-cost felt substrate. The size of the unit cell is given as $18 \mathrm{~mm}$ x $18 \mathrm{~mm}$. The gap between the unit cells is $1 \mathrm{~mm}$. The proposed antenna structure is shown in Figure 2. It is a two layered dielectric geometry made up of felt substrate with the same thickness. The view of proposed antenna with RIS shown in Figure $3 \mathrm{a}$ and $3 \mathrm{~b}$. 


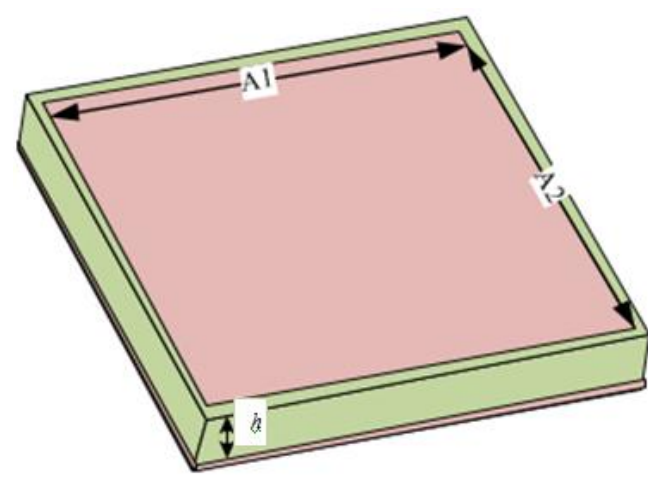

Figure 2. A unit cell of RIS

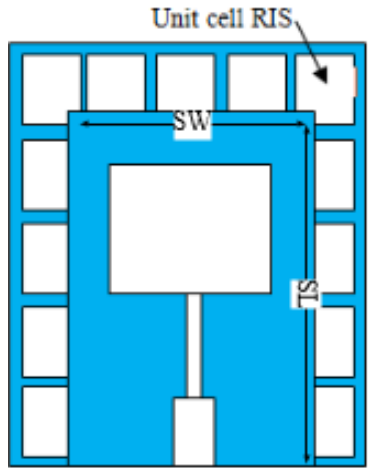

(a)

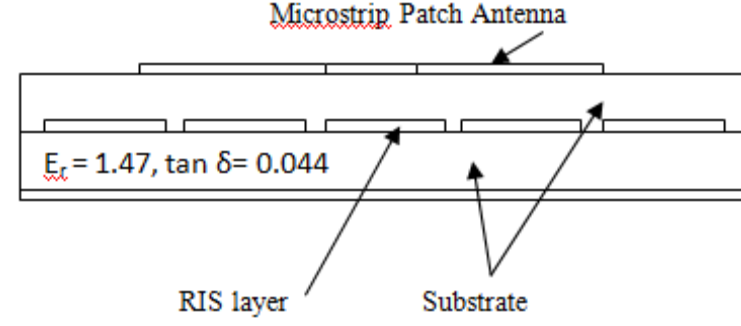

(b)

Figure 3. (a) The proposed antenna with RIS (b) side view of antenna

\section{RESULTS AND ANALYSIS}

This section presents the comparison results of both antennas, namely conventional microstrip patch antenna (MPA) and patch antenna with RIS (MPA RIS).

\subsection{Antenna Miniaturization}

The uses of RIS lead to miniaturization of the MPA. Through simulation, the size of the RIS and the patch antenna is optimized. Figure 4 shows the reflection phase of the RIS that operates near to $5.6 \mathrm{GHz}$ frequency. It operates as reactance to the MPA, thus the MPA size is reduced to match the tuning RIS reactance property. The size comparison of MPA and MPA with RIS is given in Table 2.

Figure 4 shows the simulation for reflection coefficient for both antennas. It is observed that the resonant frequency drop is close to $2.45 \mathrm{GHz}$ frequency for both of the antennas. It can be seen that the return loss for an antenna with RIS is better compared than conventional antenna where the reflection coefficient has less than $-30 \mathrm{~dB}$. Apart from that, it can be observed that MPA with RIS has the better operational bandwidth. The conventional MPA operates from $2.38 \mathrm{GHz}$ to $2.5 \mathrm{GHz}$ for $\mathrm{S}_{11}$ less than $-10 \mathrm{~dB}$. On the other hand, MPA with RIS has covered the bandwidth from $2.34 \mathrm{GHz}$ up to $2.66 \mathrm{GHz}$.

Table 2. Size comparison of MPA and MPA with RIS

\begin{tabular}{lll}
\hline Parameters & MPA & MPA with RIS ${ }^{\text {a }}$ \\
\hline Rectangular Patch (L) & $45 \mathrm{~mm}$ & $37.6 \mathrm{~mm}$ \\
Rectangular patch (W) & $55 \mathrm{~mm}$ & $50 \mathrm{~mm}$ \\
Substrate Length (SL) & $110 \mathrm{~mm}$ & $80 \mathrm{~mm}$ \\
Substrate Width (SW) & $70 \mathrm{~mm}$ & $60 \mathrm{~mm}$ \\
Substrate Thickness (H) & $3 \mathrm{~mm}$ & $3 \mathrm{~mm}$ \\
Feedline (B1) & $26.6 \mathrm{~mm}$ & $12 \mathrm{~mm}$ \\
Feedline (B2) & $6.3 \mathrm{~mm}$ & $6 \mathrm{~mm}$ \\
Quarterwave (A1) & $2.9 \mathrm{~mm}$ & $2.5 \mathrm{~mm}$ \\
Quarterwave (A2) & $27 \mathrm{~mm}$ & $20 \mathrm{~mm}$ \\
\hline
\end{tabular}




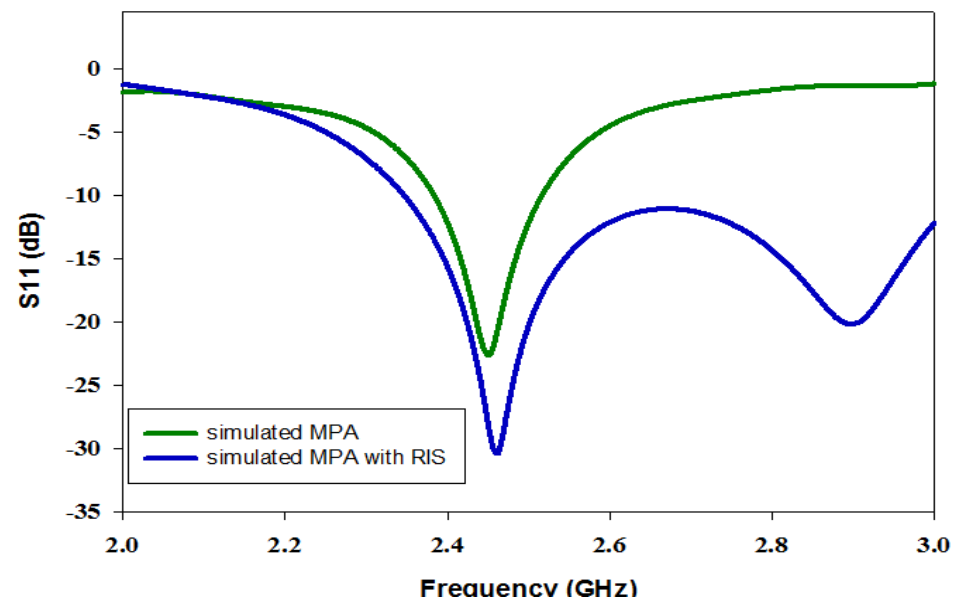

Figure 4. Reflection coefficient

Figure 5 and Figure 6 present the gain achieved by the antennas. It shows the gain is only 4.67 for MPA and the gain is increased to 6.072 when RIS is applied to the antenna.

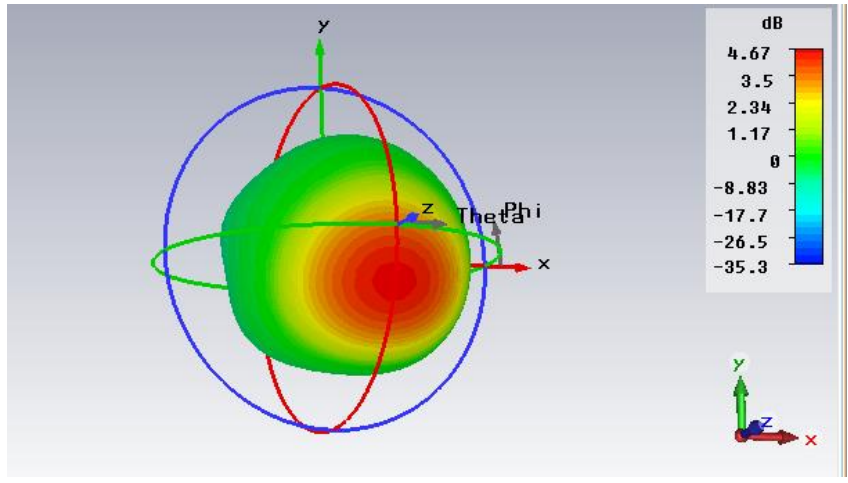

Figure 5. Gain of MPA

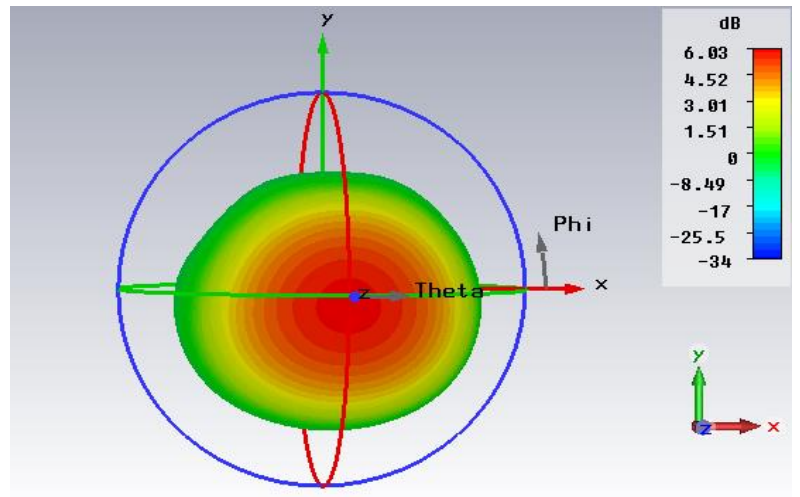

Figure 6. Gain of MPA with RIS

Table 3 summarizes the overall performance of the antenna. It shows that the antenna with RIS also improves the overall efficiency of the antenna. Next, Figure 7 depicts the simulated radiation pattern of the proposed antenna. Both antennas have directive radiation pattern but the antenna with RIS have higher gain. 


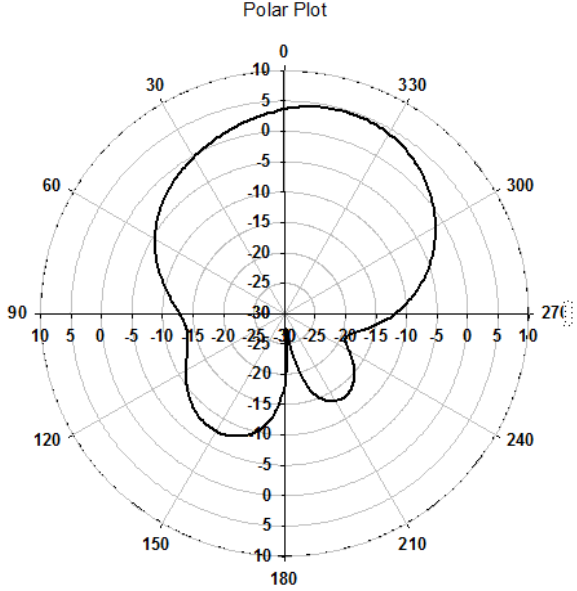

(a)

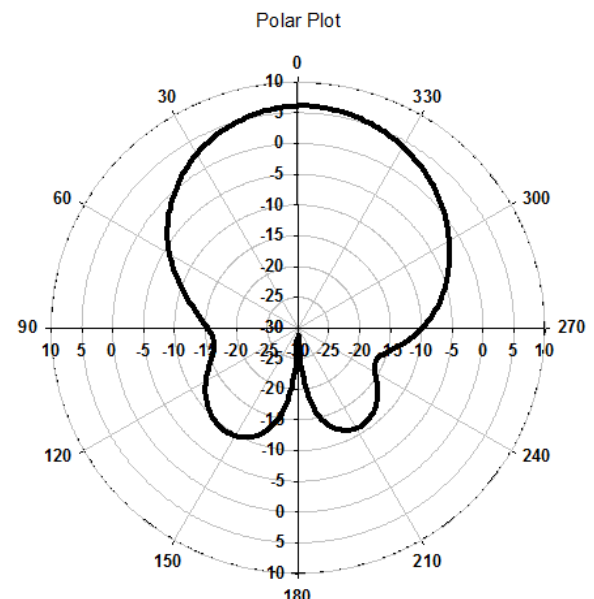

(b)

Figure 7. Simulated Radiation pattern for (a) original patch antenna and (b) antenna with RIS

Table 3. Comparison of performance for both antennas

\begin{tabular}{lll}
\hline Antenna & MPA & MPA with RIS ${ }^{\mathrm{a}}$ \\
\hline Gain (dB) & 4.67 & 6.07 \\
$\mathrm{~S}_{11}$ & -22.65 & -32.17 \\
Efficiency & $40 \%$ & $59 \%$ \\
\hline
\end{tabular}

\section{CONCLUSION}

In this paper, the development and evaluation of antenna with RIS are investigated and an antenna with better performance is proposed with the use of RIS. As a conclusion, the performance of the proposed antenna in terms of S11, gain, and efficiency is improved when RIS is applied. Gain enhancement of $20 \%$ achieved and operational bandwidth of antenna is greatly improved with use of RIS.

\section{ACKNOWLEDGEMENTS}

This work is partly supported by the Research Management and Innovation Centre of Universiti Malaysia Perlis, under fundamental research grant scheme (FRGS 9001-00569), Government of Malaysia.

\section{REFERENCES}

[1] A. K. Skivervik, J. F. Zurcher, O. Staub, J. R. Mosig. "PCS Antenna Design: The Challenge of Miniaturization," IEEE Antennas and Propagation Mag, vol. 43(4), 2001.

[2] Lee K. F., and Tong K. F., "Microstrip patch antennas-Basic characteristics and some recent advances," Proceedings of the IEEE, vol. 100(7), pp. 2169-2180. 2012.

[3] Wong Kin-Lu., "Compact and broadband microstrip antennas," vol. 168, John Wiley \& Sons, 2004.

[4] Aggarwal I., Tripathy M. R., and Pandey S., "Metamaterial inspired multiband slotted antenna for application in IOT band. In Green Engineering and Technologies (IC-GET)," 2016 Online International Conference on IEEE. pp. 1-4, Nov 2016.

[5] Chen W. S., Wu C. K., Wong K. L., "Compact circularly polarized microstrip antenna with bent slots," Electron. Lett, vol. 34, pp. 1278-1279, 1998.

[6] Bilotti F., Member S., Alú A., and Vegni L., "Design of Miniaturized Metamaterial Patch Antennas with -Negative Loading, IEEE Transactions on Antennas and Propagation, vol. 56(6), pp. 1640-1647. 2008.

[7] Shakhirul M. S., M Jusoh, Sahadah A., Nor C. M., Rahim H. A., "Embroidered wearable textile antenna on bending and wet performances for UWB reception" Microwave and Optical Technology Letters (MOTL), vol. 56(9), 2014.

[8] Zhu, Shaozhen, and Richard Langley. "Dual-band wearable textile antenna on an EBG substrate." IEEE transactions on Antennas and Propagation, vol. 57(4), pp. 926-935. 2009.

[9] H. Mosallaei and K. Sarabandi, "Antenna Miniaturization and Bandwidth Enhancement Using a Reactive," IEEE Transactions on Antennas and Propagation, vol. 52(9), pp. 2403s-2414, 2004. 